\title{
Experiências associativas de docentes e trabalhadores no Recife: $1872-1915^{1}$
}

\author{
Yan Soares Santos ${ }^{2}$
}

Adriana Maria Paulo da Silva ${ }^{3}$

\section{Resumo}

Objetivamos analisar as práticas de educabilidade voltadas às ações de educação para o trabalho, durante a segunda metade do século XIX, no Recife. Privilegiamos os registros produzidos pelos Presidentes da Província / Governadores do Estado, pelos Inspetores Gerais da Instrução Pública e os estatutos e relatórios produzidos pelas associações de trabalhadores e docentes. Analisamos as redes de relações, identificações, escolhas e experiências (THOMPSON, 1987) específicas, individuais e/ou coletivas, desses sujeitos, enquanto estratégias (DE CERTEAU, 1998) de atuação sociopolítica. Concluímos que as ações de educação para o trabalho por eles vivenciadas configuraram-se numa prática sociopolítica de seu "fazer-se" e de fortalecimento de seus ofícios específicos.

Palavras-chave: Associativismo; História Social do Trabalho; História da Educação em Pernambuco - Brasil; Século XIX.

Associative experiences of teachers and workers in Recife: 1872-1915

\section{Abstract}

We analyzed the practices of educability aimed at actions of education for work in the second half of the 19th century, in Recife. We privilege the records produced by the Presidents of the Province / Governors of the State, by the General Inspectorate of Public Education, the statutes and reports of the workers associations and teachers associations. We consider the networks of relationships, identifications, choices and experiences (THOMPSON, 1987) specific, individual and collective, of these subjects as strategies (DE CERTEAU, 1998) for their socio-political performance. We conclude that his actions to promote education for work, were the socio-political practice of his "making himself" and the strengthening of his specific jobs.

Keywords: Associativism; Social History of Work; History of Education in Pernambuco - Brazil; XIX Century.

\section{Introdução}

As províncias do norte agrário brasileiro, durante a segunda metade do século XIX, sofreram bastante as mudanças econômicas e sociais características desse período. Em função da proibição do tráfico transatlântico de escravos, dos longos períodos de secas, da queda na produção da cana de açúcar e da perda de seu valor de exportação, as alternativas para os "melhoramentos materiais" da província de Pernambuco foram escassas (MELLO, 1999). Uma alternativa a esse atraso foi o aumento do tráfico interprovincial de escravos, cuja venda para as

\footnotetext{
${ }^{1}$ Este artigo contou com o financiamento dos órgãos, por autores: Yan Soares Santos, CAPES e Adriana Mạ Paulo da Silva, CNPq.

2 Professor Substituto DFSFE/CE Universidade Federal de Pernambuco, Recife, yan.ssantos27@gmail.com.

${ }^{3}$ Professora Associada DMTE/PPGE/CE Universidade Federal de Pernambuco, Recife, adriana.mpsilva2@ufpe.br.
} 
províncias do sul, além de promover a migração de escravos para os cafezais, gerou renda para os senhores de engenho do norte agrário. Outra alternativa foi o investimento dos poderes públicos e senhores de engenho na modernização da produção açucareira na região, possibilitando a expansão do trabalho livre na província - apesar de essa modernização não ter transformado as relações de trabalho na lavoura açucareira (EISENBERG, 1977).

Tempos depois, a exportação de açúcar sofreu um declínio, em comparação com a produção cafeeira, em aumento gradual. Entre 1861-1870, o açúcar somou 12,3\% ao valor das exportações, enquanto o café mobilizou 45,5\%. Nos anos finais do Império, entre 1871-1880, a exportação do açúcar caiu para $11,8 \%$, enquanto o aumento da exportação do café alcançou 56,6\%. Na primeira década da Primeira República, entre 1891-1900, a exportação do açúcar declinou ainda mais, para $6,0 \%$ do valor das exportações, enquanto o café alcançou $64,5 \%$ dos produtos exportados (PAULA, 2012). Em 1871, calcula-se a margem de $50 \%$ de uso de mão de obra livre nas lavouras nortistas e, em $1884,75 \%$ dos trabalhadores de Pernambuco eram livres (BARBOSA, 2008).

Anteriormente à promulgação da Lei do Ventre Livre (1871), em meio às "modernizações sem mudanças" (EISENBERG, 1977), os poderes públicos desenvolveram alternativas para a libertação de crianças em cativeiro. Liberais e conservadores, juntos, encaminharam a emancipação do trabalho escravo na província. Esteve em jogo o imperativo econômico de driblar as dificuldades que assolavam a economia provincial. Tal imperativo fez as províncias nortistas se posicionarem favoravelmente às políticas de emancipação, em oposição à opinião das províncias sulistas, as quais empregavam a mão de obra escrava. Diferentemente do Sudeste, Pernambuco preocupou-se "muito mais com possíveis indenizações e medidas regulamentadoras/disciplinadoras para os ex-escravos, que seriam, gradativamente, incorporados ao mercado de trabalho livre" (BRANDÃO, 2011, p.107).

Entrecruzada com as políticas emancipacionistas, esteve a preocupação com o "ordenamento" e a "civilização" daqueles (recém-)libertos pelas leis promulgadas. Como afirmou Ilmar Mattos (2004), a preocupação com a "formação do povo" e com as vicissitudes de suas ações ocorreu concomitantemente às mudanças no cenário político e socioeconômico nacional. Mas, no horizonte dessa preocupação, as ações voltadas para o ensino de ofícios, principal esfera para o "ordenamento" e a "civilização" dos mundos da desordem e do trabalho 
(MATTOS, 2004), não foram efetivas, nem duradouras, pelo menos na província pernambucana e, em especial, no Recife (CUNHA, 2000; SANTOS, 2014).

Analisaremos as ações voltadas à instrução profissional desenvolvidas pelos poderes públicos da província pernambucana e trataremos especificamente das ações educacionais encabeçadas pelas associações de trabalhadores atuantes no Recife.

Identificamos, através da pesquisa nos registros selecionados, disputas em torno da responsabilidade da educação. Analisamos as experiências (THOMPSON, 1987) dos trabalhadores e docentes associados, as propostas e ações educacionais das associações e apresentamos nossos apontamentos críticos à historiografia sobre o associativismo e a educação para o trabalho.

\section{Ações dos poderes públicos voltadas à educação para o trabalho}

Os "Relatórios dos Presidentes de Províncias" (depois "Mensagens dos Governadores do Estado") e os "Relatórios da Instrução Pública" são fontes indispensáveis para a análise das ações dos poderes públicos voltadas à educação. Analisamos vinte e nove (29) relatórios dos presidentes da província de Pernambuco (disponíveis no site da Universidade de Chicago), de 1875 a 1889 e de 1900 a 1915 - o intervalo de dez anos, entre 1889 e 1900, não consta para acesso no site e nem no APEJE (Arquivo Público Jordão Emerenciano). Quanto aos relatórios da instrução pública, analisamos treze (13) exemplares. Destes, oito foram escritos por João Barbalho Uchôa Cavalcanti (1875; 1876; 1877; 1878; 1884; 1885; 1886; 1887); um, por Ernesto Fonseca (1878); um, por Arthur Orlando da Silva (1891); dois foram escritos por Felippe de Figuerôa Faria Sobrinho (1893; 1897); e um, por Sebastião de Vasconcellos Galvão (1905) - todos foram diretores gerais da instrução pública da província, cargo do executivo responsável por administrar, organizar, inspecionar e produzir relatórios sobre a matéria.

Com relação à instrução pública provincial, partimos da compreensão de que essa foi, durante todo o período estudado (e mesmo ao longo de toda a primeira metade do século XIX), uma prática social extremamente controlada pelos cálculos políticos dos potentados locais, em suas disputas entre si e com o conjunto da sociedade, incluindo as associações, tendo em vista a manutenção dos privilégios e das hierarquias sociais existentes. As práticas educacionais nesse período, longe de serem consideradas como "direitos" dos súditos (e, depois, dos cidadãos), 
sempre foram alvos de disputas e de alianças políticas mantenedoras - e não supressoras - das hierarquizações sociais existentes entre e intragrupos sociais (SILVA, 2007, 2013).

Em 1871, ano da promulgação da Lei do Ventre Livre, o Presidente da Província Dyogo Velho Cavalcanti de Albuquerque relatou que, com relação à educação para o trabalho sob responsabilidade do governo provincial, a província contava com quatro escolas noturnas (com 178 alunos matriculados) para a instrução da "classe obreira": os Arsenais de Guerra e Marinha, o Colégio de Órfãos e, de forma particular, os cursos mantidos pela Sociedade dos Artistas Mecânicos e Liberais, para a qual pretendia um aumento de subvenção por parte da Assembleia Legislativa (FALLA, 1871). Nesse mesmo relatório, o então Diretor Geral da Instrução Pública, em 1871, João José Pinto Júnior, referiu o "progresso" da instrução pública na província, da década de 1860 até 1871, por meio da elevação no número de matrículas e de frequência de alunos(as). Enquanto encabeçou a diretoria, promoveu a criação de mecanismos legais para o controle do ingresso na docência e da mobilidade espacial dos docentes públicos e a "liberdade de ensino": tratava-se de controlar a docência pública (regulando ao máximo os gastos com essa pasta) e liberar as ações de particulares nesse assunto (SILVA; LIMA, 2016).

Para controlar a docência pública, a Lei de Entrâncias, promulgada em 1873, coibiu as constantes solicitações dos docentes de mudarem de escolas (via de regra, saindo dos interiores para cidades cada vez mais próximas da capital), delimitando geograficamente o ingresso na docência pública concursada. No caso, docentes em início de carreira, recém-aprovados(as) nos concursos públicos da província, deveriam ser lotados(as) em escolas da chamada 1a entrância, localizadas nos "interiores" e com os menores salários do professorado público. As escolas de 2ạ entrância, com salários um pouco maiores, eram as localizadas nos subúrbios do Recife; nessas, só podiam ingressar docentes atuantes em escolas de 1a entrância. Por fim, localizadas nos bairros centrais da capital, estavam as escolas de 3 a entrância, para as quais só poderiam se candidatar docentes já atuantes nas escolas de 2aㅡ entrância. As escolas de $3 \stackrel{a}{a}$ entrância davam preferência aos docentes com maior tempo de serviço e pagavam os maiores salários. Embora o professorado da capitania/província já fosse salarialmente hierarquizado desde fins do século XVIII, a lei de entrâncias agravou ainda mais a hierarquização do exercício da docência pública (SILVA, 2007; SILVA; LIMA, 2016).

Nessa mesma lei, foi determinada a necessidade de uma "inspeção" (em lugar de um 
processo de licenciamento prévio e anual, como havia anteriormente, para a autorização do início de atividades docentes privadas) das escolas abertas e aulas ministradas por professores(as) particulares atuantes na província pernambucana. Dessa legislação em diante, o magistério particular seguiu sendo praticado livremente, quase sem nenhum tipo de controle governamental, até o fim do período estudado. O magistério público permaneceu sendo crescentemente controlado e vigiado.

No período compreendido entre 1871 e 1889, economicamente difícil para o "norte agrário", os poderes públicos da província de Pernambuco discutiram meios para sanar as dificuldades econômicas da província. Nesse intervalo, foi de fundamental importância para as ações educacionais da província a diretoria de João Barbalho Uchôa Cavalcanti, que permaneceu no cargo durante dezesseis anos, de 1874 até 1890. No ano de 1876, em seu relatório sobre as escolas de instrução profissional e técnica, afirmou existirem na província: a Escola Normal Oficial (criada em 1864 e tornada mista em 1875); a Escola de Geometria Prática (em que eram ministradas por Victor Fournié aulas de geometria e desenho linear dos arsenais de guerra e da marinha); o Liceu de Artes e Ofícios (de 1871, a cargo da Sociedade dos Artistas Mecânicos e Liberais); o Instituto Industrial Artístico e Agrícola da Colônia Orfanológica Isabel (1874-1904); aulas de obstetrícia no Hospital Pedro II e aulas de taquigrafia (FALLA, 1876).

A Escola de Geometria Prática, segundo outro relatório de Uchôa Cavalcanti, inaugurou suas atividades em 1874, passou para o prédio do Liceu de Artes e Ofícios em 1882 e foi extinta em 1883 (RELATÓRIO, 1884).

As aulas de geometria e desenho linear do arsenal de guerra iniciaram-se no ano de 1858 (MOURA, 2003). Não encontramos nenhuma menção sobre seu encerramento - nem nos relatórios dos presidentes da província/governo do Estado, nem nos jornais "Diário de Pernambuco" e "A Província" (pela hemeroteca da Biblioteca Nacional).

As aulas de obstetrícia do Hospital Pedro II iniciaram-se em 1840 (SOUSA, 2005) e foram referidas no relatório de Uchôa Cavalcanti, em 1884. Nos jornais "Diário de Pernambuco" e "A Província”, publicaram-se anúncios de abertura de matrículas nessas aulas até 1902. Em 1909, na ocasião de um congresso médico no Recife, houve a intenção de abertura de uma escola de obstetrícia no Recife e de uma maternidade no Hospital Pedro II (A PROVÍNCIA, 1909).

As aulas de taquigrafia foram inauguradas em 1874 (RELATÓRIO, 1876); o último registro 
dessas atividades foi encontrado nos relatórios de Uchôa Cavalcanti, em 1878 (RELATÓRIO, 1878). Em nenhum outro relatório de presidente da província, ou mensagem de governador do Estado, ou nos jornais consultados, houve a menção a essas aulas.

Dentre as ações consideradas pelos poderes públicos, a instrução agrícola figurou como importante campo de investimento e controle social. A Colônia Orfanológica Isabel instituiu um curso primário e agrícola para instruir profissionalmente pobres e órfãos e, inclusive, manteve parte de seus rendimentos através dos trabalhos dos próprios internos. As práticas assistencialistas, filantrópicas ou de controle social por parte dos poderes públicos recifenses iniciaram-se na primeira metade do século XIX, tendo a Colônia Isabel aglutinado, na sua criação, os extintos Colégio das Órfãs, criado em 1847, e o Colégio dos Órfãos de Santa Tereza, de 1835 (ARANTES, 2005).

Para Rodrigo Molina (2012), que investigou a instalação e o fechamento de diversas escolas agrícolas no Brasil entre 1877 e 1936, os motivos para a falência dessas instituições foram: o atraso técnico, o pouco capital aplicado em mecanizações, os períodos de secas recorrentes, a produção voltada para a exportação e a concepção pseudocientífica segundo a qual o trabalhador nacional era degenerado e improdutivo.

Depois foram criadas a Escola Agrícola Frei Caneca (1896), anexa à Colônia Orfanológica Isabel, e uma Escola de Engenharia (1895). Como empreendimentos privados funcionaram: o Liceu de Artes e Ofícios (a cargo da Sociedade dos Artistas Mecânicos); a aula de taquigrafia; a Escola Normal para Senhoras e a Escola Agrícola do Monteiro (1878), ambas a cargo da Sociedade Propagadora da Instrução Pública.

Levando em consideração os apontamentos de Peter Eisenberg sobre a "modernização sem mudanças", acreditamos que, apesar dos gastos públicos com a instalação e a manutenção da Escola Frei Caneca ao longo de seus oito anos de funcionamento (como demonstra o Quadro 1), os poderes públicos foram motivados a descontinuar a iniciativa pela falta de interesse do patronato agrícola em modificar as relações sociais de produção existentes. A modernização da produção açucareira em Pernambuco, entre os anos de 1870 e 1910, não se preocupou em transformar as relações de trabalho existentes, vinculadas à escravidão e ao trabalho compulsório (EISENBERG, 1977).

Entre os anos de 1896 e 1911, Pernambuco viveu um período de controle político, 
exercido por Francisco de Assis Rosa e Silva. Nascido em 1857, Rosa e Silva ingressou na Faculdade de Direito do Recife no ano de 1873. Em 1881, filiou-se ao Partido Conservador e nele permaneceu até 1898 , quando se tornou republicano. Foi vice-presidente da república no governo de Campos Sales e tornou-se um dos principais representantes dos interesses açucareiros. Manteve-se na política pernambucana até ser derrotado por Emídio Dantas Barreto, o qual liderou a política estadual até o ano de 1915 (SILVA, 2014).

Emídio Dantas Barreto, por sua vez, nascido em 1848, foi major do exército, tendo servido na Guerra do Paraguai e, na volta, se matriculado na Escola Militar. Também foi comandante de um batalhão na Guerra de Canudos e alcançou o generalato em 1908 (BLAKE, 1893). Em 1915, após sua vitória na disputa política pela governança do Estado de Pernambuco, Dantas Barreto fez uma declaração à Assembleia Legislativa sobre o nível "descurado" da instrução pública no Estado. Segundo o Governador, a instrução primária precisava de maior desenvolvimento, apesar de funcionarem na província dez "grupos escolares" e outros três estarem em construção (MENSAGEM, 1915).

As narrativas presentes nos "Relatórios dos Presidentes da Província" ("Mensagens dos Governadores") e nos "Relatórios da Instrução Pública" apontam para a dificuldade de garantir "bons resultados" para a instrução pública, enfrentada pelos poderes públicos. Além disso, o (pouco) investimento direto dos poderes públicos na matéria do ensino para o trabalho, por vezes, foi criticado pelas autoridades competentes e, noutros momentos, foi um assunto completamente silenciado.

O investimento indireto dos poderes públicos voltados ao ensino profissional ocorria à medida que esses concediam subvenções para as associações mantenedoras de cursos profissionais, como o Liceu de Artes e Ofícios - a cargo da Sociedade dos Artistas Mecânicos e Liberais -, a Escola Normal para Senhoras e a Escola Agrícola do Monteiro.

Os trabalhadores de ofício não recorreram às ações dos poderes públicos no campo do ensino profissional, nem mesmo exigiram atuação efetiva sobre a (possível) rubrica do direito à instrução. A estratégia (DE CERTEAU, 1998) desses trabalhadores se deu no terreno associativista. Foi através das associações que os trabalhadores se organizaram em prol de si e dos seus e instalaram cursos de ensino profissional. A onerosa manutenção dos cursos foi mote para os pedidos de subvenções e, por meio delas, as associações se fortaleceram e se protegeram. 


\section{Associados e associações: experiências estratégicas de atuação sociopolítica}

Em pesquisas anteriores voltadas a investigar a história social do trabalho, com ênfase no fenômeno associativo entre os trabalhadores, constatou-se que, apesar das condições insalubres de vida e trabalho, das disputas por mercado, da falta de reconhecimento social e da impossibilidade de subsistir e subvencionar custos básicos individuais, os trabalhadores organizaram-se em associações (MAC CORD, 2012; MAC CORD; BATALHA, 2014). Tais associações, comumente identificadas como "mutualistas", serviram para subvencionar custos básicos dos trabalhadores, bem como pugnar pela proteção do mercado de trabalho para diferentes grupos.

Nossa investigação sobre as associações atuantes no Recife dependeu da análise dos códices "Diversos II", "Folhetos Raros" e "Impressos Particulares", sob a guarda do Arquivo Público Estadual Jordão Emerenciano (APEJE). Tais códices contam com um acervo de estatutos e relatórios de algumas associações de trabalhadores de diversos ofícios, entre elas, de professores atuantes na sociedade recifense, ao longo da segunda metade do século XIX até meados do século XX.

Os estatutos são valiosos por terem sido produzidos para validar, juridicamente, a abertura e o consequente funcionamento da associação, frente aos critérios exigidos pelos poderes públicos. Normalmente os estatutos são subdivididos em: 1) fim, objeto e duração da sociedade - os artigos versam sobre as finalidades da associação, o motivo que levou os associados a abrirem a atividade; 2) organização da sociedade - como os membros serão subdivididos na associação, bem como sua hierarquia principal; 3) direção da sociedade - as responsabilidades dos membros atuantes em cargos específicos dentro da sociedade; 4) atribuições dos membros da sociedade - funções específicas dos membros, já descritas no item "2"; 5) capital da sociedade - como a associação arrecada fundos para pôr em prática suas ações, os valores específicos das joias (valor inicial para um indivíduo se tornar membro) e as mensalidades; 6) disposições gerais - quaisquer assuntos ausentes nas partes anteriores. A sequência dessas partes variava de acordo com cada associação e os títulos também podiam ser um pouco diferentes, mas o conteúdo era o mesmo e, em geral, os capítulos dos estatutos se dividiam dessa maneira. 
Nos relatórios era registrado aquilo que as associações, ao fim de certo período de atividade (normalmente um ano), decidiam publicar sobre suas ações. Abordavam, via de regra, os pontos positivos de suas ações e, comumente, relacionavam alguma atividade incompleta ou ineficaz em função da falta de verbas e/ou da falta de atenção dos poderes públicos, aos quais solicitavam, inclusive, auxílio para darem solução a essas questões.

Em Pernambuco, localizamos as seguintes associações: Sociedade dos Artistas Mecânicos e Liberais (1841); Sociedade Propagadora da Instrução Pública (1872); Grêmio dos Professores Primários de Pernambuco (1884); Sociedade Beneficente dos Machinistas de Pernambuco (1890); Associação dos Empregados no Comércio de Pernambuco (1892); Sociedade Beneficente MontePio Português (1901); Sociedade Beneficente dos Empregados da Companhia de Trilhos Urbanos do Recife, Olinda e Beberibe (1902); Sociedade Beneficente dos Empregados da Estrada de Ferro (1903); Sociedade Cooperativa dos Operários de Camaragibe (1903); Associação Comercial de Pernambuco (1904); Associação Comercial Beneficente dos Mercieiros de Pernambuco (1905); Sociedade Mútua dos Operários do Porto do Recife (1910); União Beneficente dos Caixeiros de Hotéis (1911); União de Patrões e Arraes (1911); Caixa Geral dos Proletários (1913); Sociedade Beneficente dos Empregados da Great Western (1914); Associação Beneficente do Comércio de Estivas (1918); Sociedade Beneficente dos Empregados da Western Telegraph (1919); Companhia Industrial Pernambucana (1920); Companhia Industrial de Algodão e Óleos (1921); Sociedade Beneficente União Operária (1923); Sociedade Beneficente Familiar (1926); Cooperativa Popular Pernambucana (1927); Associação Esportiva dos Funcionários do Estado (1930); Círculo Operário do Recife (1941). Estas datas referem-se aos estatutos ou relatórios encontrados no acervo, e não, aos anos de fundação ou do início do funcionamento dessas associações.

Das associações encontradas, pretendemos analisar a atuação da "Associação dos Empregados no Comércio de Pernambuco" (1892), da "Sociedade dos Artistas Mecânicos e Liberais" (1841), da "Sociedade Propagadora da Instrução Pública" (1872) e, por fim, do "Grêmio dos Professores Primários" (1878).

Utilizamos dois critérios de escolha: (a) associações com objetivos pedagógicos e (b) associações com membros em comum. Dentre as quatro escolhidas, três delas ("Sociedade dos Artistas Mecânicos e Liberais"; "Sociedade Propagadora da Instrução Pública"; "Grêmio dos Professores Primários") possuíam membros em comum. 
Essas quatro associações atuantes no Recife objetivavam em comum, principalmente, o auxílio mútuo a seus associados. Apesar disso, cada associação funcionava como um mundo próprio (vivendo e lutando para si e para os seus), sem que houvesse nenhum elo de identificação entre aqueles trabalhadores (SANTOS, 2014). O segundo objetivo dessas associações foi o de fornecer formação para seus trabalhadores, a fim de proteger o mercado de trabalho. Excetuando-se o Grêmio dos Professores Primários, tais associações abriram cursos de formação, com o propósito de proteger o mercado de trabalho apenas aos diplomados em seus cursos.

Outro traço comum entre as associações é o fato de elas terem iniciado suas atividades após a Lei do Ventre Livre, da promulgação da Lei de Entrâncias e da Lei da "Liberdade de Ensino", às quais nos referimos na primeira parte desta pesquisa. Como dissemos, a Sociedade dos Artistas Mecânicos e Liberais iniciou suas atividades ainda na primeira metade do século XIX; já o Liceu de Artes e Ofícios, sua principal ação de instrução, deu início a suas atividades na década de 1870. Acreditamos que aquele conjunto legislativo criou os condicionantes para a instalação e a manutenção dessas associações. O terreno para sua atuação na instrução profissional, se somarmos as legislações com a incipiente atuação dos poderes públicos nesse campo, nunca tinha estado tão fértil.

A "Sociedade dos Artistas Mecânicos e Liberais" (SAML), atuante no Recife desde 1841, foi fundada por antigos mestres carpinteiros e carapinas, tendo surgido ainda como Confraria da Igreja de São José de Ribamar, localizada no Bairro de São José. Um dos objetivos dessa sociedade foi o auxílio mútuo dos seus associados (MAC CORD, 2012). Desde sua instalação, procurou abrigar cursos para o ensino profissional de seus trabalhadores, ação condizente com seu primeiro objetivo associativo: o "aperfeiçoamento" mais amplo dos associados, ou seja, a instrução para o ofício. Em 1851 modificou seus estatutos, passou a incorporar todos os artistas mecânicos, ampliou suas aulas e promoveu exames de habilitação de seus alunos, com a participação do Presidente da Província. Foi durante a Presidência da Província exercida por Manoel do Nascimento Machado Portella que a SAML ficou encarregada de comandar o Liceu de Artes e Ofícios de Pernambuco, em finais da década de 1870. Essa associação construiu estratégias para impulsionar-se ao bojo da "boa sociedade" recifense, demonstrando a preferência por suas ações e valorizando seus associados. Desde o final da década de 1860, a 
SAML recebeu subvenção dos poderes públicos para financiar suas ações de instrução profissional. Foi por meio da ampla subvenção pelos cofres públicos e das doações de particulares que a SAML pôde construir o "palacete", na parte privilegiada do centro do Recife, que abrigou (e abriga) o Liceu de Artes e Ofícios (MAC CORD, 2012).

Talvez, seguindo a experiência dos trabalhadores de ofícios mecânicos, a "Associação dos Empregados no Comércio de Pernambuco" (AECP), instalada em 1886, declarou o interesse de "reunir em um grêmio fraternal os empregados no mesmo comércio, protegê-los e às suas famílias, instruí-los e pugnar pelos interesses legítimos de cada um deles e pelos da classe em geral, empregando os recursos a seu alcance" (COMÉRCIO, 1892, p.3). Essa proteção financeira era para as situações de doenças, invalidez ou, em caso da morte do associado, sua família receberia certo ordenado.

Na sessão "fins da associação", o segundo parágrafo do primeiro artigo dos estatutos dizia: “§2은 Instruirá seus associados, estabelecendo um curso noturno para o ensino de matérias necessárias à instrução comercial e de outras que forem reclamadas por vinte sócios, no mínimo" (COMÉRCIO, 1892, p.3). Não temos relatórios dessa associação entre esses anos, porém, em 1903, identificamos a abertura dos cursos ainda como uma intenção da associação em seus estatutos, segundo os quais:

“§ 50 Manterá as aulas mais indispensáveis para a instrução comercial, organizando um curso regular, moldado nos primeiros do gênero, logo que tenha meios para isso. O regulamento será organizado pelo seu diretor, discutido e aprovado pelo corpo docente e submetido depois à aprovação do conselho diretor" (COMÉRCIO, 1903, p.4).

Segundo Felipe Souza, o perfumista Manoel Eugênio da Rocha Samico, presidente da AECP em 1907, foi contemplado, em maio de 1889, com um privilégio exclusivo de oito anos para montar uma fábrica de perfumes e sabonetes (SOUZA, 2020). O perfumista compôs a chapa lançada pela Liga Operária Pernambucana para a eleição da constituinte e para a intendência municipal, em 1890. A atuação da Liga Operária Pernambucana voltou-se para uma agenda conciliatória com a elite local (SOUZA, 2020). O jogo político daqueles trabalhadores seguiu as estratégias de alianças desenvolvidas anos antes pelos artífices do liceu. Para o autor, alguns consócios da Liga Operária, por participarem de outras irmandades religiosas e associações 
mutualistas, adentraram a rede do "associativismo negro" ${ }^{4}$, pela predominância de homens de cor naqueles espaços.

Recorrendo tanto aos jornais da cidade quanto à base de dados Family Search, nossa pesquisa observou que, dos poucos sócios cujos nomes foram listados nos estatutos e relatórios de três associações pesquisadas, não há informações sobre as suas cores ${ }^{5}$. A exceção foram os sócios da Sociedade dos Artistas Mecânicos e Liberais, cuja predominância de pretos e pardos é largamente conhecida e foi evidenciada pela fotografia da inauguração do palacete do Liceu analisada e publicada por Marcelo Mac Cord (MAC CORD, 2012) ${ }^{6}$.

Para nós, é incontornável a relação do associativismo mutualista, principalmente do associativismo negro com as propostas e ações voltadas à educação. A educação foi - e é compreendida como possibilidade de ascensão social e conquista de mobilidade pela população de cor no Brasil (e no mundo ocidental), tanto no Império, quanto na Primeira República, direcionando-a (possivelmente) às práticas de liberdade e ampliação de direitos de cidadania (SILVA, 2000; SILVA, 2018).

Espalhadas pelas províncias do Império (e estados da República), as mutualistas instalaram escolas de ensino primário e profissional. Segundo Alessandra Schueler, a proposta

\footnotetext{
${ }^{4}$ Petrônio Domingues destacou a diversidade de agenciamento da comunidade negra e parda organizada a fim de pugnar por direitos - civis, políticos e sociais - ou atividades coletivas recreativas, como, por exemplo, a Sociedade Liga dos Homens de Cor, a Guarda Negra, o Club Republicano dos Homens de Cor e o Grêmio Literário Treze de Maio, instaladas no Rio de Janeiro. Petrônio denominou aquelas agremiações enquanto partícipes do "associativismo negro" (2014).

${ }^{5}$ Como alertou Álvaro Nascimento, a historiografia social do trabalho silenciou a "cor" dos/as trabalhadores/as investigados/as, reduzindo a pesquisa à branquidade e à mestiçagem, crendo e fazendo crer no falho discurso segundo o qual as associações mutualistas - compostas por pretos e pardos - "atrasaram" a "formação do movimento operário" (NASCIMENTO, 2016; MAC CORD; BATALHA, 2014). Seguindo o alerta de Álvaro, além dos casos relatados no corpo do texto, fizemos a pesquisa nominal dos associados da AECP, dos professores do Liceu e dos professores associados da SAML e no GPPP, e não obtivemos ocorrências promissoras. Em relação à $A E C P$, o sócio Antonio Jesuino de Souza Martins apareceu nos jornais em 1898 como secretário da Venerável Ordem 3a do Seráphico Padre S. Francisco, no Recife (FBN. Diário de Pernambuco, domingo, 14 de agosto de 1898, p.5); já Tito Livio da Silva foi secretário da Sociedade Recreativa Magdalenense, em 1890 (FBN, Diário de Pernambuco, 9 de novembro de 1890, p.5); por sua vez, Augusto Gonçalves Fernandes apareceu na seção "subscrição portuguesa" (FBN, Diário de Pernambuco, 15 de maio 1890, p.2), indicando uma associação diversa em cor e nacionalidade - sobre a questão da nacionalidade entre trabalhadores do comércio no Recife: cf.: Bruno Câmara (CÂMARA, 2012). No Arquivo Público Estadual Jordão Emerenciano (APEJE), não há registros de inventários post-mortem e certidões de óbitos em seu acervo, segundo seus catálogos. Cf.: NASCIMENTO, A. P. Trabalhadores negros e o "paradigma da ausência": contribuições à História Social do Trabalho no Brasil. Estud. hist. (Rio J.), Rio de Janeiro, v. 29, n. 59, p.607-626, Dec. 2016. Available from <http://www.scielo.br/scielo.php?script=sci_arttext\&pid=S0103-21862016000300607\&lng=en\&nrm=iso>. access on 04 Aug. 2020. DOI: https://doi.org/10.1590/s2178-14942016000300003.

${ }^{6}$ Dentre aqueles "homens de cor" consócios do Liceu, o professor Félix de Valois Correia também foi sócio da Sociedade Propagadora da Instrução Pública e do Grêmio dos Professores Primários, e foi o único que fez referência a sua cor (MAC CORD, 2012, p.408; AUTOR, 2014; AUTOR (ES) X, 2017).
}

Periódico Horizontes - USF - Itatiba, SP - Brasil - e021011 
"pedagógica" da Sociedade Propagadora da Instrução pelas Classes Operárias da Lagoa, no Rio de Janeiro, englobou crianças menores de 14 anos, adultos analfabetos e escravos (SCHUELER, 1997). Segundo Aldrin Castellucci, associações de trabalhadores negros soteropolitanos fundaram escolas de ensino noturno, durante a Primeira República (CASTELLUCCI, 2008). O Liceu de Artes e Ofícios da Bahia, também composto por homens de cor, como dissemos, pertenceu à Sociedade de Artes e Ofícios da Bahia (1872), cuja instalação foi conduzida por Joaquim do Nascimento Machado Portella (LEAL, 1995), antigo presidente da província de Pernambuco e entusiasta das ações promovidas pela SAML de Pernambuco (MAC CORD, 2012). Marcelo Mac Cord, Itacir Luz e Wendel Costa foram os responsáveis por analisarem as experiências vivenciadas pelos homens de cor agremiados na Sociedade dos Artistas Mecânicos e Liberais, desde a sua instalação (1841) até os anos 1908 (LUZ, 2008; MAC CORD, 2012; COSTA, 2013).

No ano de 1911, a Associação dos Empregados no Comércio de Pernambuco inaugurou uma "Academia do Comércio". Seu objetivo foi fornecer instrução técnica às pessoas interessadas na carreira comercial, nos empregos de fazenda, na administração e nas empresas. O curso foi dividido em três momentos: o primeiro era um curso elementar; o segundo, um curso secundário; e o terceiro, um curso superior (COMÉRCIO, 1911). Apesar de o artigo 5o do documento de instalação autorizar a quaisquer pessoas a realização, com ônus, de quaisquer cadeiras nesses cursos, isso não garantia aos "não associados" uma diplomação (COMÉRCIO, 1911). A academia também nutriu relação conciliatória com os poderes públicos recifenses, devido à subvenção de três contos de réis (3.000\$) que recebia da Prefeitura do Recife para a própria manutenção (RELATÓRIO, 1921).

Apesar da ênfase no controle das contas públicas, os poderes públicos da Província/Estado de Pernambuco mantiveram o costume de "apoiar" as ações voltadas à instrução, mantidas por particulares (SANTOS, 2014). As subvenções, como principal meio de "apoio", auxiliaram na manutenção das associações, nas suas ações em prol de si e dos seus, através dos cursos para a instrução profissional. Desde a década de 1860, a Sociedade dos Artistas Mecânicos e Liberais havia sido "agraciada" com uma subvenção. Logo nos primeiros anos de funcionamento da Academia do Comércio de Pernambuco, a instituição conseguiu, a cargo da Associação dos Empregados no Comércio de Pernambuco, o auxílio, por meio de uma subvenção pública. A prática de conferir subvenções a particulares atravessou diferentes governos, do Império à República. 
A estratégia das associações de proferirem, em seus estatutos, suas intenções de abertura de cursos de instrução foi longeva, como também foram as próprias ações de instrução por elas instaladas. A "Sociedade Propagadora da Instrução Pública" (SPIP) foi inaugurada em 11 de agosto de 1872 e o evento ocorreu no Palácio da Presidência da Província, com a presença de 180 pessoas "ilustres" da sociedade recifense (Diário de Pernambuco, 1872). Aquelas pessoas "ilustres" da "boa sociedade" recifense exerciam cargos nos chamados conselhos paroquiais da associação. Esses conselhos, divididos entre os bairros do Recife, gozavam de certa independência (em relação ao Conselho Superior) quanto às suas decisões e ações em prol da instrução primária, porém deveriam apresentar ao Conselho Superior da SPIP um balanço anual. Entre os sócios atuantes nos conselhos paroquiais constavam alguns que também eram membros da "Sociedade dos Artistas Mecânicos e Liberais", como era o caso de Joaquim Lopes Machado, João L. Dornellas Câmara e do próprio Manoel do Nascimento Machado Portella (SANTOS, 2014).

Ainda no ano de sua instalação, a SPIP inaugurou também a Escola Normal para Senhoras (1872). Seis anos depois, em 1878, abriu uma Escola Agrícola no bairro do Monteiro (subúrbio do Recife) e, em 1903, inaugurou uma Escola de Farmácia. Essas ações foram logo nomeadas como as da "primeira fase" da associação, intitulada (nada modestamente) de "irradiação de atividades educacionais em todos os sentidos" (PÚBLICA, 1940, p.2-3).

A "Propagadora" figurou como um caso interessante. A associação, além de ter sido encabeçada por João José Pinto Júnior - o mesmo político que fez vingar a "lei das entrâncias" e a da "liberdade de ensino" -, ainda enquanto na Diretoria da Instrução Pública de Pernambuco, contou com a "camada superior" da docência pública, em exercício nas escolas de 3a entrância do Recife, nas quais atuavam os docentes mais experientes e mais bem remunerados. $O$ próprio presidente da província Manoel do Nascimento Machado Portella esteve entre os sócios fundadores da iniciativa. A associação recebeu uma subvenção de 120 contos de réis, com os quais promoveu suas ações.

Relacionando a "Lei da Liberdade de Ensino" com os condicionantes da "Lei do Ventre Livre" e com a iniciativa dos poderes públicos da província de libertar meninas antes mesmo da aprovação dessas leis, acreditamos que a instalação da Sociedade Propagadora da Instrução Pública figurou como uma ação da "elite" pernambucana em prol da direção da "formação do povo" (MATTOS, 2004), mantendo-a, por meio de subvenções. 
Logo no início de suas atividades, a Escola Normal para Senhoras (da associação) determinou, por meio da Lei 1.143, de 8 de junho de 1874, em seu artigo 536, que o diploma conferido pela escola isentava de exame de habilitação as alunas para exercerem o magistério, equiparando-se, portanto, à Escola Normal Oficial da província (PERNAMBUCO, 1874). Compreendemos que aquela escola de formação de professores controlada por uma associação de particulares tinha o mesmo poder de certificação e de colocação de egressos no mercado de trabalho que aquele conferido à instituição controlada pelos poderes públicos. Em 1882, a Lei 1636 conferiu à Escola Normal da SPIP plena autonomia quanto à aprovação da capacidade de suas alunas e ampliou o status do seu curso frente à sociedade pernambucana. Acreditamos que a Escola Normal foi a responsável por disseminar as concepções de instrução da própria SPIP, renovando o quadro de professoras na província e articulando ainda mais a intrincada rede de sociabilidade da própria empreitada associativista (SANTOS, 2014), além de irradiar seu dispositivo de "formação do povo" (VARELA; ALVAREZ-ÚRIA, 1991; MATTOS, 2004). Entretanto, apesar desta "equiparação", do ponto de vista das subvenções recebidas, de acordo com os dados obtidos para fins do século XIX, os recursos públicos do Estado de Pernambuco direcionaram-se muito mais para a Escola Normal Oficial, conforme podemos ver no quadro 1 a seguir.

Quadro 1 - Orçamento aproximado da Instrução Pública comparada às subvenções para associações (1896-1915)

\begin{tabular}{|l|l|l|l|l|l|l|}
\hline Ano & $\begin{array}{l}\text { Escola } \\
\text { Normal } \\
\text { Oficial }\end{array}$ & $\begin{array}{l}\text { Subvenção à } \\
\text { Sociedade } \\
\text { dos Artistas } \\
\text { Mecânicos e } \\
\text { Liberais }\end{array}$ & $\begin{array}{l}\text { Subvenção à } \\
\text { Sociedade } \\
\text { Propagadora } \\
\text { da Instrução } \\
\text { Pública }\end{array}$ & $\begin{array}{l}\text { Escola de } \\
\text { Engenharia } \\
\mathbf{( 1 8 9 5 )}\end{array}$ & $\begin{array}{l}\text { Escola Frei } \\
\text { Caneca } \\
\mathbf{( 1 8 9 6 )}\end{array}$ & $\begin{array}{l}\text { Orçamento } \\
\text { da } \\
\text { Instrução } \\
\text { Pública }\end{array}$ \\
\hline 1896 & $63.739 \$$ & $5.000 \$$ & $5.000 \$$ & $87.000 \$$ & $1.155 .200 \$$ & $64.400 \$$ \\
\hline 1898 & $91.510 \$$ & $5.000 \$$ & 0 & $87.400 \$$ & $350.000 \$$ & $941.960 \$$ \\
\hline 1899 & $78.250 \$$ & $5.000 \$$ & 0 & $10.340 \$$ & $363.900 \$$ & $818.840 \$$ \\
\hline 1901 & $84.640 \$$ & $5.000 \$$ & $3.000 \$$ & $122.025 \$$ & 0 & $666.152 \$$ \\
\hline 1902 & $83.360 \$$ & $5.000 \$$ & $3.000 \$$ & $127.400 \$$ & $348.900 \$$ & $833.081 \$$ \\
\hline 1903 & $83.600 \$$ & 0 & 0 & $123.400 \$$ & $254.200 \$$ & $774.901 \$$ \\
\hline 1904 & $83.633 \$$ & 0 & 0 & $123.400 \$$ & $259.600 \$$ & $766.724 \$$ \\
\hline 1905 & $86.480 \$$ & 0 & 0 & 0 & 0 & $590.210 \$$ \\
\hline 1910 & $88.080 \$$ & $2.500 \$$ & $6.000 \$$ & 0 & 0 & $604.104 \$$ \\
\hline 1915 & $90.000 \$$ & $5.000 \$$ & $3.000 \$$ & 0 & 0 & $772.025 \$$ \\
\hline
\end{tabular}

Fonte: Decretos de Lei e Regulamentos e Legislação Estadual de Pernambuco: APEJE? .

\footnotetext{
7 PERNAMBUCO, Decreto de Lei e Regulamentos. Lei N. 121. Acervo Impresso. CAIXA 2. APEJE. (1891-1896, não contínuo); PERNAMBUCO, Decreto de Lei e Regulamentos. Lei N. 249. Acervo Impresso. CAIXA 2. APEJE. (1891-1896,
} 
Dentre os condicionantes para a implementação da Escola Agrícola do Monteiro, a cargo da SPIP, elegemos as posturas dos políticos e empresários agrícolas da província, voltadas com mais afinco para a questão da agricultura pernambucana. Em 1871, o presidente da província, Dyogo Velho Cavalcanti de Albuquerque, na seção do relatório referente à agricultura, chamou a atenção para o seguinte fato: "a lavoura é para Pernambuco, como para o Brasil, o que o sangue é para o corpo humano - o princípio vital do organismo" (FALLA, 1871. p.35). Para ele, muitos problemas afetavam a agricultura, no entanto, a falta de braços e a dificuldade de substituição da mão de obra escrava pelo trabalhador livre eram os principais desafios da economia agrícola. A solução não estava apenas na procura de uma nova força de trabalho disponível, o fundamental seria o perfil dessa força de trabalho. Não por acaso deu-se a defesa da criação de uma escola profissional agrícola.

Em 1878, sete anos depois daquela fala de Dyogo Albuquerque, o então presidente da província em exercício, Adolfo de Barros Cavalcanti, relatava o movimento das aulas apenas da Colônia Isabel, bem como as subvenções públicas em prol dessa instituição. A seca que assolava a província desde 1876 não havia cessado e as intervenções do governo provincial eram imprescindíveis. Outra colônia agrícola, a do Socorro, era composta por uma série de famílias vindas de outras "províncias do norte" (o Nordeste ainda não havia sido "inventado" na ocasião), realocadas em lotes pelo ministro da Agricultura para produzir e trabalhar na construção de uma estrada ligando Palmares à colônia (FALLA, 1878; ALBUQUERQUE JR, 1999).

A Escola Agrícola, da Sociedade Propagadora da Instrução Pública, foi aberta a partir da Escola Primária e da Biblioteca Anexa, no Monteiro, subúrbio do Recife. Nesse bairro, foi instalado o Conselho Paroquial (CP) do Poço da Panela, talvez o CP mais efetivo em atividades de ensino profissional da SPIP. Consultando um memorial da SPIP de 1895 sobre o funcionamento do curso agrícola, soubemos que vinte alunos participaram daquele curso em

não contínuo).; PERNAMBUCO, Decreto de Lei e Regulamentos. Lei N. 315. Acervo Impresso. CAIXA 2. APEJE. (18911896, não contínuo).; PERNAMBUCO, Legislação Estadual. Lei N. 472. Orçamento de 1901. Estante 29, Prateleira 04, № 89, Ano 1900-1905.; PERNAMBUCO, Legislação Estadual. Lei N. 523. Orçamento de 1902. Estante 29, Prateleira 04, № 89, Ano 1900-1905.; PERNAMBUCO, Legislação Estadual. Lei N. 579. Orçamento de 1903. Estante 29, Prateleira 04, № 89, Ano 1900-1905.; PERNAMBUCO, Legislação Estadual. Lei N. 637. Orçamento de 1904. Estante 29, Prateleira 04, № 89, Ano 1900-1905.; PERNAMBUCO, Legislação Estadual. Lei N. 682. Orçamento de 1905. Estante 29, Prateleira 04, № 89, Ano 1900-1905.; PERNAMBUCO, Legislação Estadual. Lei N. 986. Orçamento 1910. Estante 29, Prateleira 04, № 91, Ano 1900/1909.; PERNAMBUCO, Decreto de Lei e Regulamentos. Lei 1095. Orçamento 1911. Acervo Impresso. CAIXA 6. APEJE.; PERNAMBUCO, Legislação Estadual. Lei N. 1236. Orçamento 1915. Estante 29, Prateleira 04, № 91. 
1878, tendo chegado, inclusive, a arborizar o local das aulas (MEMORIA, 1892).

Em 1884, João Barbalho Uchôa Cavalcanti, inspetor geral da instrução pública, reclamou do pequeno subsídio voltado ao ensino agrícola, tanto por parte dos poderes públicos quanto da iniciativa particular, e alertou para o fato de que as aulas primárias deveriam prover conhecimentos básicos de agricultura aos que fossem fazer profissão na lavoura (RELATÓRIO, 1884. p.20). Ele não parecia interessado em "fazer doutores em agricultura"; pelo contrário, seu interesse era "fazer somente agricultores habilitados", pois o ensino, na sua perspectiva, deveria ter caráter "experimental e prático" (RELATÓRIO, 1884. p.21).

As ações da Sociedade Propagadora da Instrução Pública incluíram a abertura de uma Escola de Farmácia, em 1903. Anos depois, essa escola desvencilhou-se da associação que a inaugurou, alegando desprezo dos consócios com o ensino de farmácia, e seguiu com forte influência sobre a comunidade médica do Recife - por ter fundado a Faculdade de Medicina do Recife. A Escola Agrícola, por sua vez, parece não ter funcionado por muito tempo e, aparentemente, não conseguiu cumprir a intenção de formar trabalhadores para a agricultura, capazes de superar as mazelas persistentes, muito menos logrou êxito em manter os trabalhadores agrícolas em seus locais de trabalho, para evitar a migração para os centros urbanos, antes e após a abolição da escravidão (SANTOS, 2014).

Aos 25 de março de 1878, um grupo de professores primários instalou o "Grêmio dos Professores Primários", cuja seção inaugural ocorreu na sede da "Sociedade dos Artistas Mecânicos e Liberais" (MAC CORD, 2012, p.317). O propósito da sociedade era o de "promover o aperfeiçoamento da instrução primária na província, fazendo conferências pedagógicas, nas quais eram discutidas as reformas e medidas convenientes à transmissão do ensino e a qualquer assunto concernente à instrução" (PERNAMBUCO, 1883, p.383). Como sócios efetivos, foram matriculados professores públicos e particulares da instrução primária para trabalhadores de ambos os sexos. Como sócios honorários, foram aceitos professores secundários ou funcionários superiores da instrução. Um montepio - uma forma de poupança das associações junto a bancos estatais - foi criado e conservado, a fim de amparar os sócios efetivos, sem aposentadoria em tempos de moléstias, e os que ultrapassassem o período de licença com vencimentos. Tal recurso objetivava, também, amparar as famílias em caso de morte do sócio - procedimento comum às associações de característica beneficente e mutualista (ESTATUTOS, 1878). O primeiro 
presidente do "Grêmio" foi Vicente de Moraes Mello, professor público do Recife e também sócio da SPIP.

No primeiro estatuto do "Grêmio", foi perceptível a urgência de relacionar aqueles professores que poderiam fazer parte do quadro de sócios entre os efetivos, correspondentes, honorários e beneméritos, seguida da forma como se organizariam as funções burocráticas da associação. Apenas no capítulo III dos estatutos foram descritos seus "fins". O primeiro "fim" da associação era: "Art. 13. § 1 - o aperfeiçoamento da instrução primária e do magistério que a professa" (PRIMÁRIOS, 1878, p.9). Para mantê-lo, a associação estabeleceu que: a) haveria reuniões mensais do conselho da sociedade; b) manteria a publicação da Revista do Grêmio dos Professores Primários; c) fundaria uma biblioteca pedagógica para uso do professorado recifense; d) participaria dos debates políticos sobre as regulações sobre o ensino; e) sobre a uniformização do ensino primário; f) organizaria o montepio (a tática de auxílio mútuo da associação).

As publicações assinadas pelos membros do "Grêmio", na revista da própria associação, continham artigos cujos temas extrapolavam suas duas finalidades centrais, o aperfeiçoamento da instrução primária e o montepio para o amparo dos sócios. Os artigos tratavam tanto de questões pedagógicas, como de aspectos escolares e ações empreendidas pelas diferentes instâncias governamentais. Inferimos que o "Grêmio" pugnou em prol da instrução primária na província e se inseriu no debate público provincial com uma voz singular (SANTOS; LIMA; SILVA, 2017).

Nos primeiros anos da República, membros do Liceu de Artes e Ofícios publicaram duas revistas. Nas edições, intituladas “O Brazil Artístico" (1896) e “O Trabalho" (1900), discorreu-se principalmente sobre a valorização do trabalho artífice - contribuinte do desenvolvimento das ciências. Nos impressos não houve qualquer menção à questão da "cor" dos associados e dos trabalhadores de ofícios atuantes no mercado de edificações do Recife. A questão comum da defesa expressa dos homens de cor nas associações negras cariocas e paulistas (DOMINGUES, $2010 ; 2014)$ não foi destaque nos assuntos das poucas tiragens dos impressos vinculados ao Liceu do Recife. Concordamos com Marcelo Mac Cord, o qual defende que aqueles artífices recifenses utilizaram estratégias que os dissociassem dos estigmas da escravidão e do fardo de sua cor, evidenciando que "não eram ex-escravos e libertos sem clara ocupação profissional, nem 
amedrontavam o 'mundo da ordem'” (MAC CORD, 2012, p.409, grifos no original). A disputa dos trabalhadores de ofício pela cidadania ativa, as relações verticais ascendentes com a política local e a constante reafirmação do "valor" de seu trabalho centralizaram seus esforços ininterruptos de atuação na esfera pública.

Analisando as intenções manifestadas pelas associações de trabalhadores de ofícios docentes, comerciais e artífices elencadas nesta sessão, consideramos que: apesar das condições insalubres de vida e trabalho, das disputas por mercado, da falta de reconhecimento social e da impossibilidade de subsistir e subvencionar custos básicos individuais, os trabalhadores e docentes organizaram-se em associações as quais, através de ações para a educação de si mesmas e dos seus, protegeram e tentaram monopolizar a oferta de seus serviços profissionais - meio pelo qual conquistaram benefícios, como as subvenções dos poderes públicos.

\section{Apontamentos finais}

As diversas sociedades de ofício atuantes na cidade do Recife, ao longo do século XIX, definiram como objetivo principal o auxílio mútuo dos seus associados, em cada uma delas, e propuseram cursos. Defendemos que as experiências vividas e interpretadas (THOMPSON, 1987) por aqueles sujeitos condicionaram sua organização em associações de ofício e que suas ações foram estrategicamente urdidas e direcionadas, especificamente, para cada uma delas, sem nenhuma relação (de parceria ou solidariedade) com as demais. Mesmo entre aquelas associações que partilhavam sócios em comum, as ações de parceria e de solidariedade entre eles, que poderiam levá-los, por exemplo, a se identificarem em geral como "professores", como "docentes" da província, tendo em vista as práticas educacionais efetivadas pelas associações, não ocorreram. Diferentemente disso, cada associação, nos limites de sua atuação, manteve-se relativamente contida dentro dos valores hierarquizadores que separavam as pessoas e os lugares no Império do Brasil e nos primeiros anos da República. Em comum, atuaram usando as ações para a formação escolarizada de seus membros, com o intuito de favorecê-los, proteger, controlar e monopolizar a oferta de seus serviços profissionais. 


\section{Referências}

A PROVÍnCIA. Congresso médico. Recife, Quarta-feira, 28 de abril de 1909, p.1, ed. 94. Disponível em:

http://memoria.bn.br/DocReader/DocReader.aspx?bib=128066_01\&pasta=ano\%20190\&pagfis =19475. Acesso em: 26 fev. 2021.

ALBUQUERQUE JR., D. M. A invenção do nordeste e outras artes. Recife/ São Paulo: FJN, Ed. Massangana/Cortez, 1999.

ARANTES, A. S. O papel da colônia orfanológica Isabel na educação e na definição dos destinos de meninos negros, brancos e índios na Província de Pernambuco (1874-1889). Recife, PE: UFPE, 2005.

BARBOSA, A. F. A formação do mercado de trabalho no Brasil. São Paulo: Alameda, 2008.

BLAKE, A. V. A. S. Diccionário bibliographico brasileiro, vol. 2. Rio de Janeiro: Typographia Nacional, 1893. Disponível em: http://www2.senado.leg.br/bdsf/item/id/221681. Acesso em: 01 jun. 2018.

BRANDÃO, S. Ventre livre, mãe escrava: a reforma social de 1871 em Pernambuco. 3. ed. Recife: Ed. Universitária da UFPE, 2011.

CASTELUCCI, A. A. S. Trabalhadores, máquina política e eleições na Primeira República. Salvador: UFBA, 2008.

COSTA, W. R. Instruir, disciplinar e trabalhar: a Sociedade dos Artistas Mecânicos e Liberais de Pernambuco e o Liceu de Artes e Ofícios (1880-1908). Recife: UFRPE, 2013.

COMÉRCIO, A. E. Estatutos da Associação dos Empregados no Comércio de Pernambuco. Pernambuco: Tipografia do Jornal do Recife, 1892. (APEJE: Folhetos Raros II).

COMÉRCIO, A. E. Estatutos da Associação dos Empregados no Comércio de Pernambuco. Pernambuco: Tipografia do Jornal do Recife, 1903. (APEJE: Folhetos Raros II).

COMÉRCIO, A. Estatutos da Academia do Comércio de Pernambuco. Recife: Typografia do Diário de Pernambuco, 1911. (APEJE: Códice, Folhetos Raros II).

CUNHA, L. A. O ensino industrial-manufatureiro no Brasil. Rev. Bras. Educ., Rio de Janeiro, n.14, p.89-107, ago. 2000. Disponível em:

http://www.scielo.br/scielo.php?script=sci_arttext\&pid=S1413-

24782000000200006\&lng=en\&nrm=iso. Acesso em: 05 nov. 2018. DOI: http://dx.doi.org/10.1590/S1413-24782000000200006. 
DE CERTEAU, M. A invenção do cotidiano: 1. Artes de fazer. 17. ed. Petrópolis, RJ: Vozes, 2011.

DIÁRIO de Pernambuco. Sábado 10 de agosto de 1872. Diário de Pernambuco 1 out. a 31 dez. 1872, rolo n.98. (FUNDAJ - setor de microfilmagem).

DOMINGUES, P. Esses intimoratos homens de cor: o associativismo negro em Rio Claro (SP) no pós-abolição. História Social, n.19, p109-134. 2010.

DOMINGUES, P. Cidadania por um fio: o associativismo negro no Rio de Janeiro (1888-1930).

Bras. Hist., São Paulo, v.34, n.67, p.251-281, jun. 2014. Disponível em:

http://www.scielo.br/scielo.php?script=sci_arttext\&pid=S0102-

01882014000100012\&lng=es\&nrm=iso. Acesso em: 04 ago. 2020. DOI:

http://dx.doi.org/10.1590/S0102-01882014000100012.

EISENBERG, P. Modernização sem mudança: a indústria açucareira em Pernambuco: 18401910. São Paulo: Paz e Terra, 1977.

ESTATUTOS do Grêmio dos Professores Primários em Pernambuco. Recife: Typografia do Tempo, 1878.

FALLA recitada na abertura da Assembleia Legislativa de Pernambuco pelo Exc. Presidente da Província Conselheiro Diogo Velho Cavalcanti de Albuquerque no dia 1ㅇ de março de 1871. Recife: Typographia de M. F. de F. e Filhos, 1871.

FALLA com que o Exm. Sr. Desembargador Henrique Pereira de Lucena abriu a sessão da Assembléia Províncial, Março 1876. Disponível em: http://www.crl.edu/ptbr/brazil/provincial/pernambuco Último acesso em: 07/03/2021.

FALLA com que o Exm. Sr. Dr. Adolfo de Barros Cavalcanti, Presidente da Província, abrio a sessão da Assembleia Legislativa em 19 de dezembro de 1878. Recife: Typographia de Manoel Figueirôa da Faria \& Filhos, 1878.

LEAL, M. G. A. A arte de ter um ofício: Liceu de Artes e Ofícios da Bahia (1872-1972). Salvador: UFBA, 1995.

LUZ, I. Compassos letrados: profissionais negros entre instrução e ofício no Recife (1840-1860). João Pessoa: UFPB, 2008.

MAC CORD, M. Artífices da cidadania: mutualismo, educação e trabalho no Recife oitocentista. Campinas: Editora da Unicamp, 2012.

MAC CORD, M.; BATALHA, C. Organizar e proteger: trabalhadores, associações e mutualismo no Brasil (séculos XIX e XX). Campinas: Editora da Unicamp, 2014. 
MATTOS, I. R. O tempo saquarema: a formação do Estado imperial. Rio de Janeiro: HUCITEC, 2004.

MELLO, E. C. O norte agrário e o Império 1871-1889. Rio de Janeiro: Toopbooks, 1999.

MEMÓRIA sobre os fatos mais importantes da vida da Sociedade Propagadora da Instrução Pública em Pernambuco. Acompanhado de menções honrosas e artigos relativos ao 20응 aniversário da mesma sociedade. Publicação do Conselho Superior em homenagem ao glorioso acontecimento. Pernambuco, 1892. (CX 19. R. 3.167/85. Códice Folhetos Raros II, APEJE).

MENSAGEM do Exm. Sr. General Emydio Dantas Barreto, Governador do Estado, lida por ocasião da instalação da 3으 sessão da 8 o legislatura do Congresso Legislativo do Estado, aos 6 de março de 1915. Recife: Typographia do Jornal do Recife, 1915. Disponível em: http://www.crl.edu/pt-br/brazil/provincial/pernambuco Último acesso em: 07/03/2021.

MOLINA, R. S. Primeiras escolas agrícolas no Brasil: limites e falências (1877-1936). Revista HISTEDBR Online, Campinas, n.46, p.309-324, jun. 2012.

MOURA, V. L. B. Pequenos aprendizes: assistência à infância desvalida em Pernambuco no século XIX. 2003, f. 171. Dissertação (Mestrado em História) - Universidade Federal de Pernambuco, Recife, 2003.

NASCIMENTO, A. P. Trabalhadores negros e o "paradigma da ausência": contribuições à História Social do Trabalho no Brasil. Estud. hist. (Rio J.), Rio de Janeiro, v. 29, n. 59, p.607-626, Dec. 2016. Available from <http://www.scielo.br/scielo.php?script=sci_arttext\&pid=S010321862016000300607\&lng=en\&nrm=iso>. access on 04 Aug. 2020. https://doi.org/10.1590/s2178-14942016000300003.

PAULA, J. A. O processo econômico. In: CARVALHO, J. M. (org.). A construção nacional: 18301889. Rio de Janeiro: Editora Objetiva, 2012. (História do Brasil Nação: 1808-2010).

PÚBLICA, S. P. I. Memorial da Sociedade Propagadora da Instrução Pública. Recife: Petição, 1940. (APEJE: Códice, Petições).

RELATÓRIO apresentado ao Exm. Sr. Presidente da Província em 31 de janeiro de 1876, pelo Inspetor Geral João Barbalho Uchôa Cavalcanti. Recife: Typographia de Manoel Figueirôa de Faria \& Filhos, 1876. Disponível em: http://www.crl.edu/pt-br/brazil/provincial/pernambuco. último acesso em: 07/03/2021.

RELATÓRIO apresentado ao Exm. Sr. Presidente da Província em 31 de outubro de 1878, pelo Inspetor Geral João Barbalho Uchôa Cavalcanti. Recife: Typographia de Manoel Figueirôa de Faria \& Filhos, 1878. Disponível em: http://www.crl.edu/pt-br/brazil/provincial/pernambuco Último acesso em: 07/03/2021.

RELATÓRIO da Associação dos Empregados no Comércio de Pernambuco relativo ao ano de 
1919. Recife: Imprensa Industrial, 1921. (S.D.I.- Dep.01- Est.52- P.05- Env.01. Códice Folhetos Raros, Diversos II, APEJE).

RELATÓRIO da Instrução Pública apresentado ao Exm. Sr. Presidente da Província pelo Inspetor Geral João Barbalho Uchôa Cavalcanti. Recife: Typographia de Manoel de Figueroa Faria \& Filhos, 1884.

SANTOS, Y. S. A sociedade propagadora da instrução pública e suas ações de qualificação profissional em Recife (1872-1903). Recife: UFPE, 2014.

SANTOS, Y. S. LIMA, D. R. P. SILVA, A. M. P. Imprensa e docência em Pernambuco, 1883-1884. In: CONGRESSO BRASILEIRO DE HISTÓRIA DA EDUCAÇÃO. 9. 2017, Recife. Anais [...]. João Pessoa: Universidade Federal da Paraíba, 2017, p.4504-4522.

SCHUELER, A. Educar e instruir: a instrução popular na corte imperial -1870 a 1889. 1997, $250 f$. Dissertação (Mestrado em História) - Universidade Federal Fluminense, Niterói, 1997.

SILVA, A. L. Caminhos da liberdade: os significados da educação dos escravizados. Isso. Bras. Educ., Rio de Janeiro, v.23, 2018. Disponível em: http://www.scielo.br/scielo.php?script=sci_arttext\&pid=S141324782018000100255\&lng=en\&nrm=iso. Access em: 04 ago. 2020. DOI: https://doi.org/10.1590/s1413-24782018230067.

SILVA, A. M. P. Aprender com perfeição e sem coação: uma Escola para meninos pretos e pardos na corte. Brasília: Editora Plano, 2000.

SILVA, A. M. P. Processos de construção das práticas de escolarização em Pernambuco, em fins do século XVIII e primeira metade do século XIX. Recife: Editora Universitária da UFPE, 2007.

SILVA, A. M. P. Notas para o estudo da instituição da obrigatoriedade da educação primária na província de Pernambuco. In: VIDAL, D. G.; SÁ, E. F.; SILVA, V. L. G. (orgs.). Obrigatoriedade escolar no Brasil. Cuiabá: Ed UFMT, 2013, p.209-226.

SILVA, A. M. P.; LIMA, D. R. P Mobilidade espacial e resistência dos(as) docentes públicos(as) primários(as) do Recife (1860-1880). Revista Tópicos Educacionais, v.1, p. 22-44, 2016.

SILVA, S. V. Anotações para uma visão de Pernambuco no início do século XX. Recife: Editora da UFPE, 2014.

SOUSA, P. S. M. As parteiras e os médicos: a inserção do gênero masculino numa realidade feminina (século XIX e início do século XX). Recife: UFPE, 2005.

SOUZA, F. A. A blusa e a urna: metamorfoses do associativismo de trabalhadores em Pernambuco entre o Império e a República. Mundos do Trabalho, Florianópolis, v.12, p.1-18, mar. 2020. Disponível em: 
https://periodicos.ufsc.br/index.php/mundosdotrabalho/article/view/1984-9222.2020.e71472. Acesso em: 06 ago. 2020. DOI: https://doi.org/10.5007/1984-9222.2020.e71472. ISSN 19849222.

THOMPSON, E. A formação da classe operária, vol.1: a árvore da liberdade. Rio de Janeiro: Paz e Terra, 1987.

VARELA, J. Y; ALVAREZ-ÚRIA, F. Arqueologia de la escuela. Madrid: Endymion, 1991.

Recebido em julho 2019.

Aprovado em outubro 2020. 